\title{
Patent landscape of neglected tropical diseases: an analysis of worldwide patent families
}

\author{
Folahanmi Tomiwa Akinsolu1*, Vitor Nobre de Paiva ${ }^{2}$, Samuel Santos Souza ${ }^{3}$ and Orsolya Varga ${ }^{1}$
}

\begin{abstract}
Background: "Neglected Tropical Diseases" (NTDs) affect millions of people in Africa, Asia and South America. The two primary ways of strategic interventions are "preventive chemotherapy and transmission control" (PCT), and "innovative and intensified disease management" (IDM). In the last 5 years, phenomenal progress has been achieved. However, it is crucial to intensify research effort into NTDs, because of the emerging drug resistance. According to the World Health Organization (WHO), the term NTDs covers 17 diseases, namely buruli ulcer, Chagas disease, dengue, dracunculiasis, echinococcosis, trematodiasis, human African trypanosomiasis, leishmaniasis, leprosy, lymphatic filariasis, onchocerciasis, rabies, schistosomiasis, soil-transmitted helminthes, taeniasis, trachoma, and yaws.

The aim of this study is to map out research and development (R\&D) landscape through patent analysis of these identified NTDs. To achieve this, analysis and evaluation have been conducted on patenting trends, current legal status of patent families, priority countries by earliest priority years and their assignee types, technological fields of patent families over time, and original and current patent assignees.

Main body: Patent families were extracted from Patseer, an international database of patents from over 100 patent issuing authorities worldwide. Evaluation of the patents was carried out using the combination of different search terms related to each identified NTD.

In this paper, a total number of 12,350 patent families were analyzed. The main countries with sources of inventions were identified to be the United States (US) and China. The main technological fields covered by NTDs patent landscape are pharmaceuticals, biotechnology, organic fine chemistry, analysis of biological materials, basic materials chemistry, and medical technology. Governmental institutions and universities are the primary original assignees.

Among the NTDs, leishmaniasis, dengue, and rabies received the highest number of patent families, while human African trypanosomiasis (sleeping sickness), taeniasis, and dracunciliasis received the least. The overall trend of patent families shows an increase between 1985 and 2008, and followed by at least 6 years of stagnation.
\end{abstract}

Conclusion: The filing pattern of patent families analyzed undoubtedly reveals slow progress on research and development of NTDs. Involving new players, such as non-governmental organizations may help to mitigate and reduce the burden of NTDs.

Keywords: Neglected tropical diseases, Patents, Preventive chemotherapy, Intensified disease management, Mass drug administration

\footnotetext{
* Correspondence: folahanmi.tomiwa@sph.unideb.hu

'Department of Preventive Medicine, Faculty of Public Health, University of

Debrecen, Debrecen, Hungary

Full list of author information is available at the end of the article
} 


\section{Background}

In Africa, Asia and South America, a good number of the population adds to the hundreds of millions of people affected by "neglected tropical diseases" (NTDs). According to the World Health Organization (WHO), the term NTDs covers the following 17 diseases: buruli ulcer, Chagas disease, dengue, dracunculiasis (guineaworm disease), echinococcosis, trematodiasis, human African trypanosomiasis (sleeping sickness), leishmaniasis, leprosy, lymphatic filariasis, onchocerciasis (river blindness), rabies, schistosomiasis, soil-transmitted helminthes, taeniasis, trachoma, and yaws [1]. Based on the efforts of few researchers (e.g. Prof. Peter Hotez, Prof. Alan Fenwick and Prof. Alan Fairlamb), the concept of an umbrella category of these diverse diseases was established in the aftermath of the Millennium Development Goals (2000). In 2010, the WHO launched its first report on NTDs defining the strategic approaches for reducing the burden of NTDs [2]. Two years later, a "roadmap" was published revealing the milestones set for 2015 and 2020. The "roadmap" specifies targets for the eradication, elimination and intensified control of identified NTDs [3, 4].

For NTDs, the two primary methods of interventions are "preventive chemotherapy and transmission control" (PCT) covering "mass drug administraion" (MDA), and "innovative and intensified disease management" (IDM). In case of PCT, global strategies and applicable tools are readily available [5]. The most important tool for control is the administration of inexpensive (usually donated) drugs to entire at-risk populations without prior individual diagnosis [6]. PCT allows the regular and coordinated administration of single dose medicines on a large scale for the treatment of dracunculiasis, leprosy, lymphatic filariasis, onchocerciasis, schistosomiasis, soil-transmitted helminthiases and trachoma. IDM focuses more on NTDs for which simple tools and treatments are not yet available in which wide scale prevention cannot be applied (eg. effective drug does not exist or the high risk population cannot be reached) [7]. Some of the NTDs addressed by itensified disease management include buruli ulcer, Chagas disease, human African trypanosomiasis (sleeping sickness), leishmaniasis and yaws (endemic treponematoses) [4].

The MDA program is part of the PCT, and it involves regular drug donations. Several pharmaceutical companies, such as Merck \& Co., Pfizer, GlaxoSmith etc. have been donating key drugs to address NTDs since the mid-1980s. In the case of Merck \& Co., there is a program to donate Mectizan $^{\odot}$ indefinitely to support the fight of onchoceriasis [8]. From a recent WHO report on "Unprecedented progress against NTDs", 1 billion people have been treated for at least one NTD in 2015 alone [9]. In spite of the success of MDA programs, they are controversial and raise important issues for consideration, such as suboptimal coverage or lack of efficacy [10]. Another concern about MDA programs is that they have been linked to drug and insecticide resistance experienced in the veterinary field $[11,12]$. In fact, resistance to drugs has been detected in many parasites highlighting the risk of developing drug resistance when a single drug is used and the drug pressure is high [13]. Thus, drug donation cannot ameliorate the deficiency of new chemical entities being researched and developed. Taking on these challenges, the London Declaration (2012) based on governments, charities, and pharmaceutical companies aims to facilitate research and development (R\&D) beyond ensuring the necessary supply of drugs and other interventions for NTDs for which treatments already exist. Tables 1, 2 and 3 shows the global data on number of countries affected by NTDs, disease burden, major interventions including information on prevention, treatment, drug resistance and donation, and effectiveness of interventions.

According to the Global Burden of Disease 2015 study [14], the overall disability-adjusted life-years (DALYs) (an important parameter of disease burden) between 2005 and 2015, due to NTDs substantially declined. For example, DALYs of human African trypanosomiasis, a disease targeted for elimination has been reduced by more than $70 \%$ since 2005 . However, the epidemiological improvement is not uniform. For example, both total and age-standardised DALYs rates for dengue increased by more than $50 \%$.

The aim of this study is to determine the trends of R\&D on NTDs by performing a patent landscape analysis. Historically, patents encourage research by giving monopoly to inventors over invention for 20 years and disclosing these inventions for public use after this period of time. To obtain a patent, an inventor must file a patent application. A patent application does not automatically give the applicant a temporary right against infringement. A patent has to be granted for it to be effective and enforceable against infringement. Performing a patent landscape analysis is an established method for understanding $R \& D$ trends in the biomedical field. This is because innovations stemming from biomedical research possess a great potential for developments which are often subjected to patent filings [15]. Additionally, due to novel, user friendly data visualization technologies and publicly accessible patent databases, patent landscape analysis has become an available tool for researchers and stakeholders to investigate emerging areas and also to identify economically attractive research gaps [16]. Considering the wide variety of contents available in patents, they are essential source of information for technological analysis $[17,18]$. Although, technical possibilities for creating patent landscapes improved a lot in the last years, today only a limited number of patent landscapes are addressing comprehensive questions on health topics [19]. 


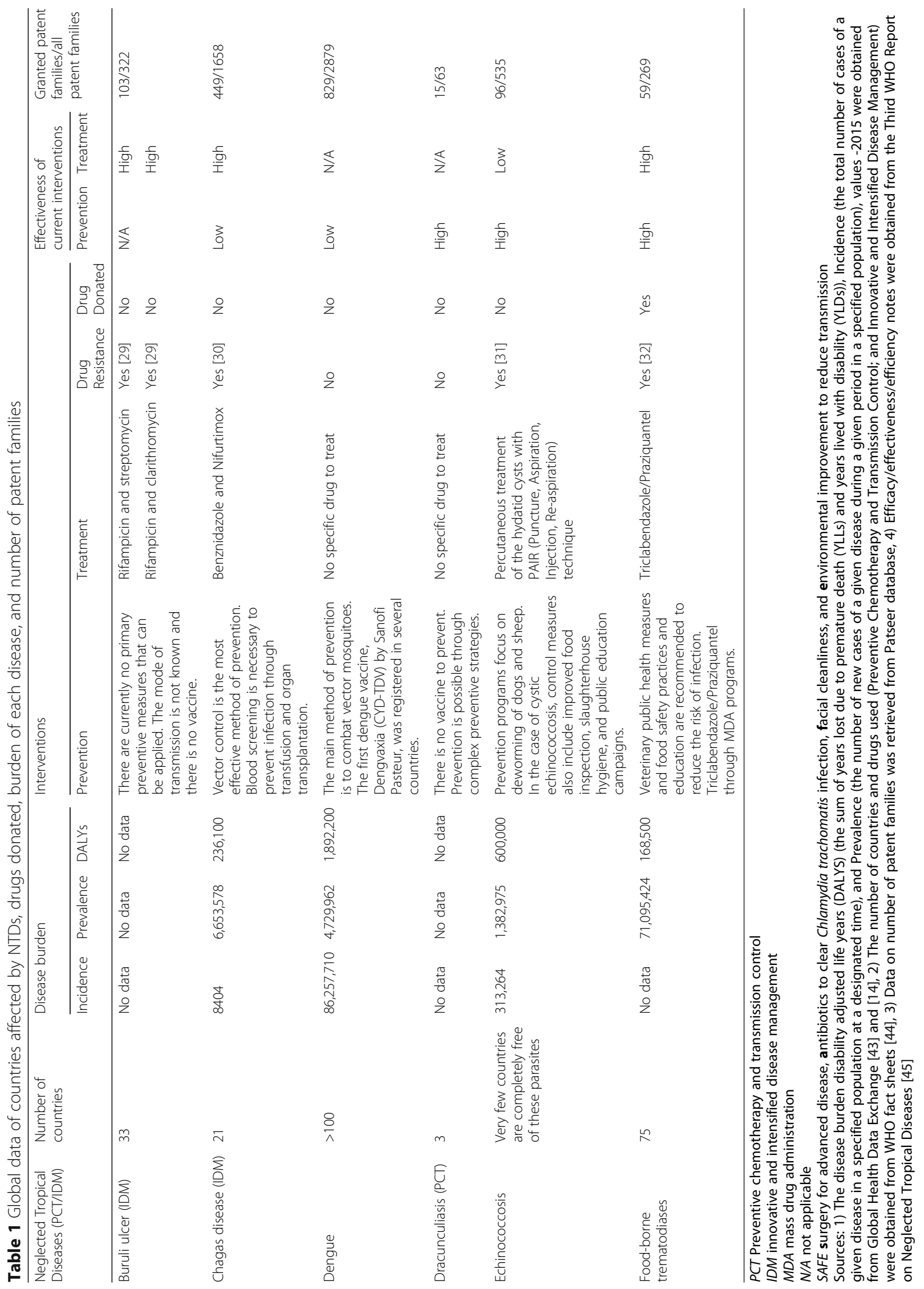




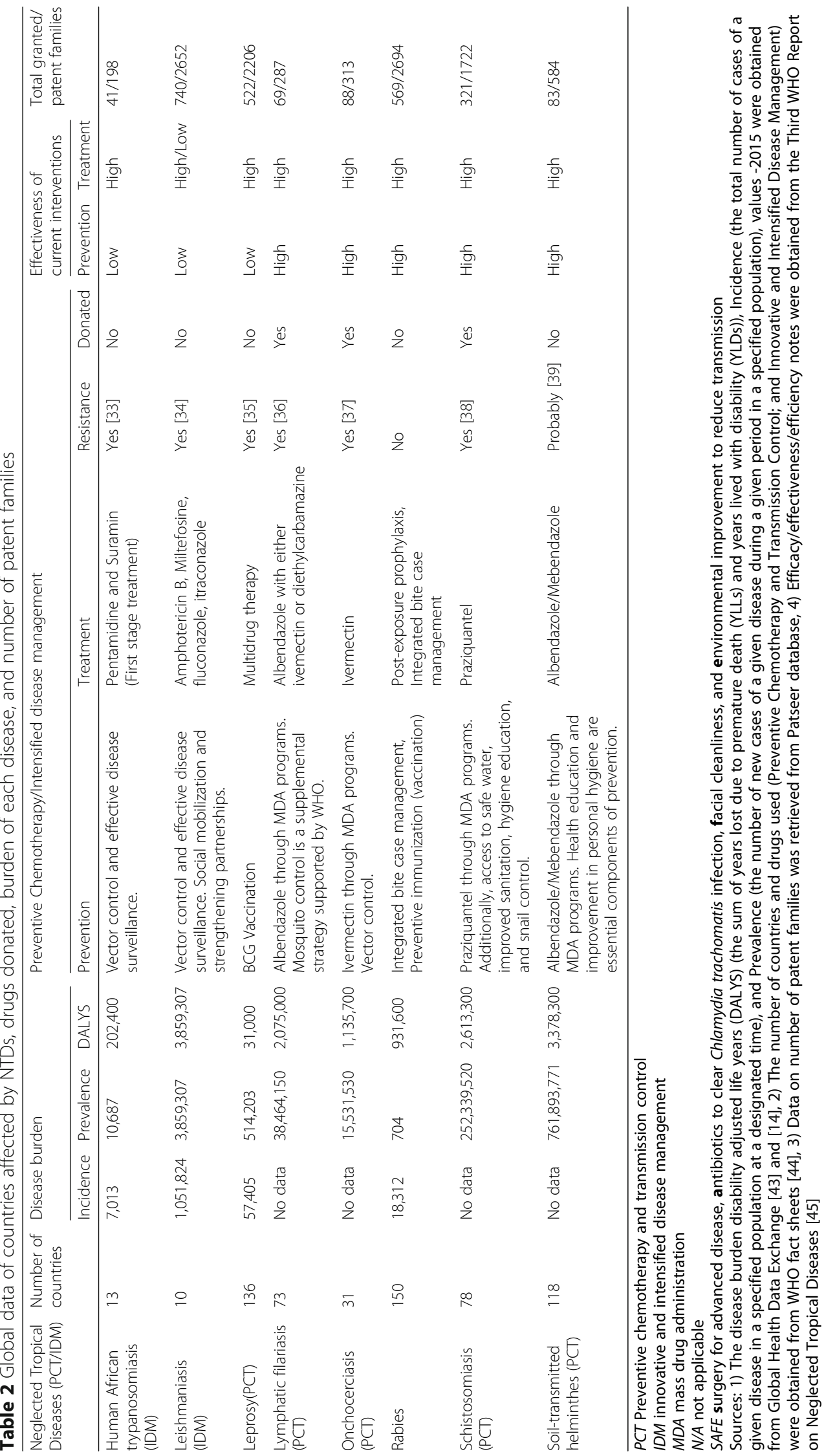




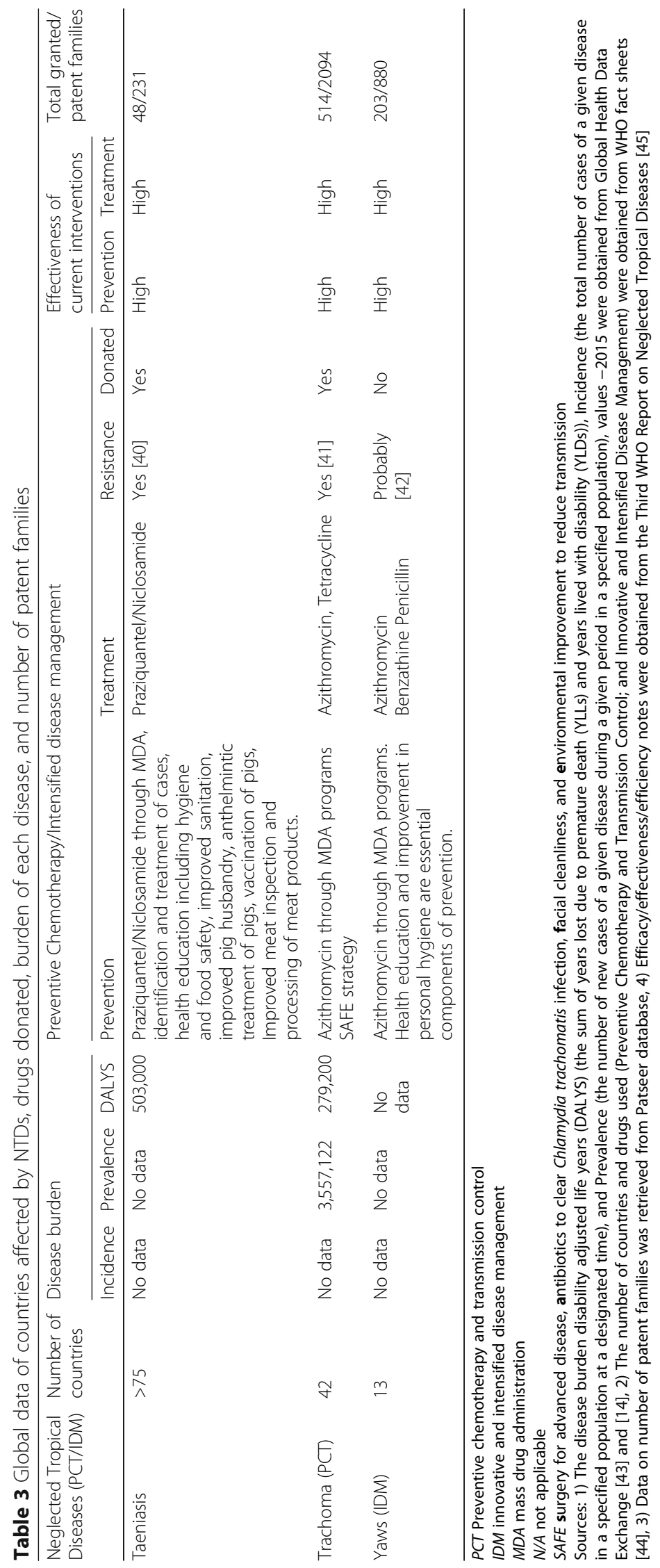




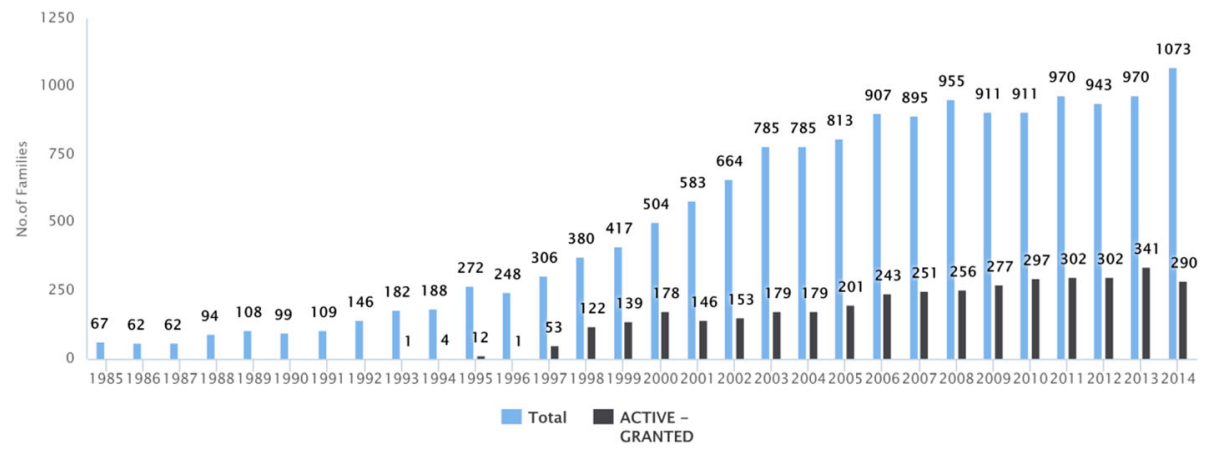

Fig. 1 Patenting trend by number of granted patent families and the total patent families. The overall filing trend in the last 30 years for NTDs reveals an increasing trend between 1985 and 2014. Following the intense growing period between 1985 and 2008, there is no steady increase in the number of total patent families, but there is a slow but continous growth in the number of granted patent families. Patent applications are not published until after 18 months, this explains why no data is presented after 2014

This analysis addressed the patenting trends, current legal status of patents, priority countries by earliest priority years and their assignee types, technological fields of patent families over time, and lastly, original and current patent assignees in the last 30 years.

\section{Methods}

Patent families have been extracted from Patseer, an international database of patents from over 100 patent issuing authorities worldwide [20]. Evaluation of the patent families has been carried out using the combination of different search terms related to each identified NTD. The final set of keywords is presented in Additional file 1. Keywords of each identified NTD (their synonyms and truncation to cover different endings, singular/plural etc.) have been obtained from the Medical Subject Headings (MeSH) database of the National Library of Medicine in which vocabulary thesaurus is used for indexing articles for PubMed, fact sheets relating to NTDs produced by the WHO, and Google Scholar.

For visualization purposes of R\&D trends, an additional database and software, PatBase [21] was also used; the patent collection retrieved from Patseer was uploaded and analyzed in PatBase.

Technology domains and International Patent Codes (IPC) have been adopted for topic identification for each identified NTD. Technology domains are comprehensive allocations of patented inventions. The first 4 digits of IPC codes are linked with the 35 fields of technology, in which categorization has been revised by the World Intellectual Property Organization [22]. The IPC categorizes similar inventions thus, providing a single source to browsing through all inventions relating to a specific NTD using the titles, abstracts and claims of patent families have been accessed.

The analysis was based on simple patent families (a group of one or more patent applications which represent the same invention) since patent applications are often filed in more than one country. Duplicates have been removed by creating simple families which represent the family members of a particular patent record with same priority dates.

Legal status information is an important component of patent information, as it determines whether

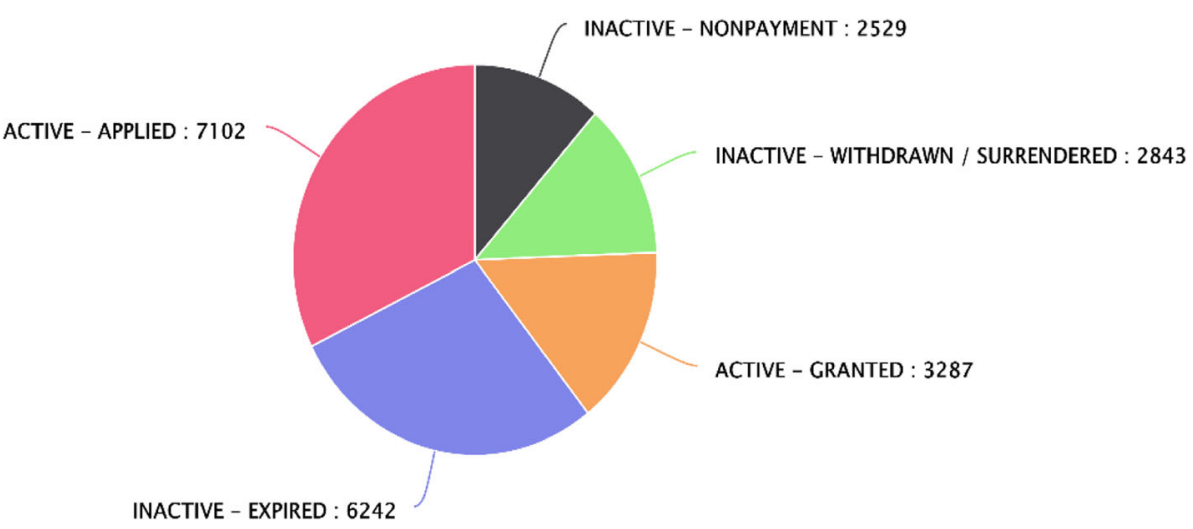

Fig. 2 Current legal status of patent families of NTDs. Almost $50 \%$ of the patents are not active. Record numbers refer to the number of patent families 

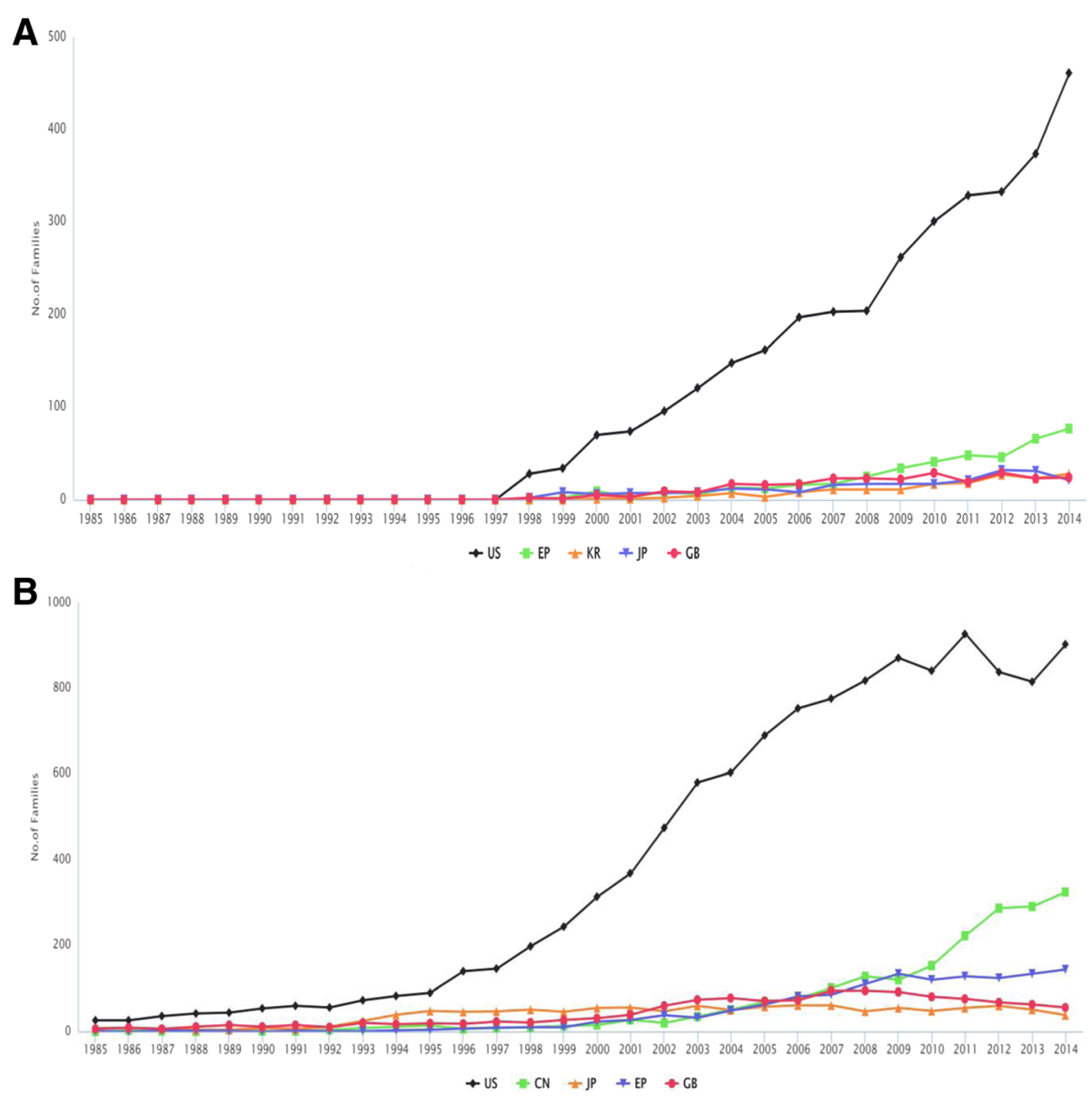

Fig. 3 Number of granted patent families (a) and the total patent families (b) for the top five priority countries, by years. a: Main countries with source of inventions are the United States and the European Union-European Patent Office. Record numbers refer to the number of granted patent families. Priority countries are: US (United States), EP (European Union-European Patent Office), KR (Korea), JP (Japan), GB (Great Britain). b: Main countries with source of inventions are the United States and China. Record numbers refer to the number of patent families. Priority countries are: US (United States), CN (China), JP (Japan), EP (European Union-European Patent Office), GB (Great Britain)

examination of a patent application is still pending, or the application was withdrawn or rejected, or a patent has been granted and it is still valid or a granted patent has expired, lapsed or been revoked due to an opposition. In PatSeer, setting "one member per family" deduplication mode for an entered query, the displayed record is represented by the legal status of its family members. For example, if any one of the family members has legal status as granted, the record displayed will be marked as granted.

\section{Results}

In this study, the total number of patent families reviewed was 12,350 , out of which 3179 were granted patent families. A distinction between research activities for each NTD has been observed. Among the NTDs, leishmaniasis, dengue, and rabies received the highest number of families, while taeniasis and dracunciliasis the least. The number of granted patent families and total patent families for each NTD is presented in Table 1. The overall patenting trend for NTDs is often characterized by the total number of simple families and granted patent families (by year when it was granted). As presented in Fig. 1, there is a substantial increase in patenting activities between 1985 and 2014 both in the total numbers of patent families including applications and in granted patent families. Although, total patenting activity was fluctuating between 2003 and 2008 which was followed by 6 years stagnation, mainly because of the decreasing number of applications. The increase in the granted families is continuous but slow.

The variable trends in NTDs patenting can be classified into three distinguished catergories. The first category shows an increasing trend in the number granted patents based on patent families (buruli ulcer, Chagas disease, dengue, onchocerciasis); the second category is mostly characterized by stagnation (echinococcosis, leishmaniosis, leprosy, rabies, schistosomiasis, trachoma, 


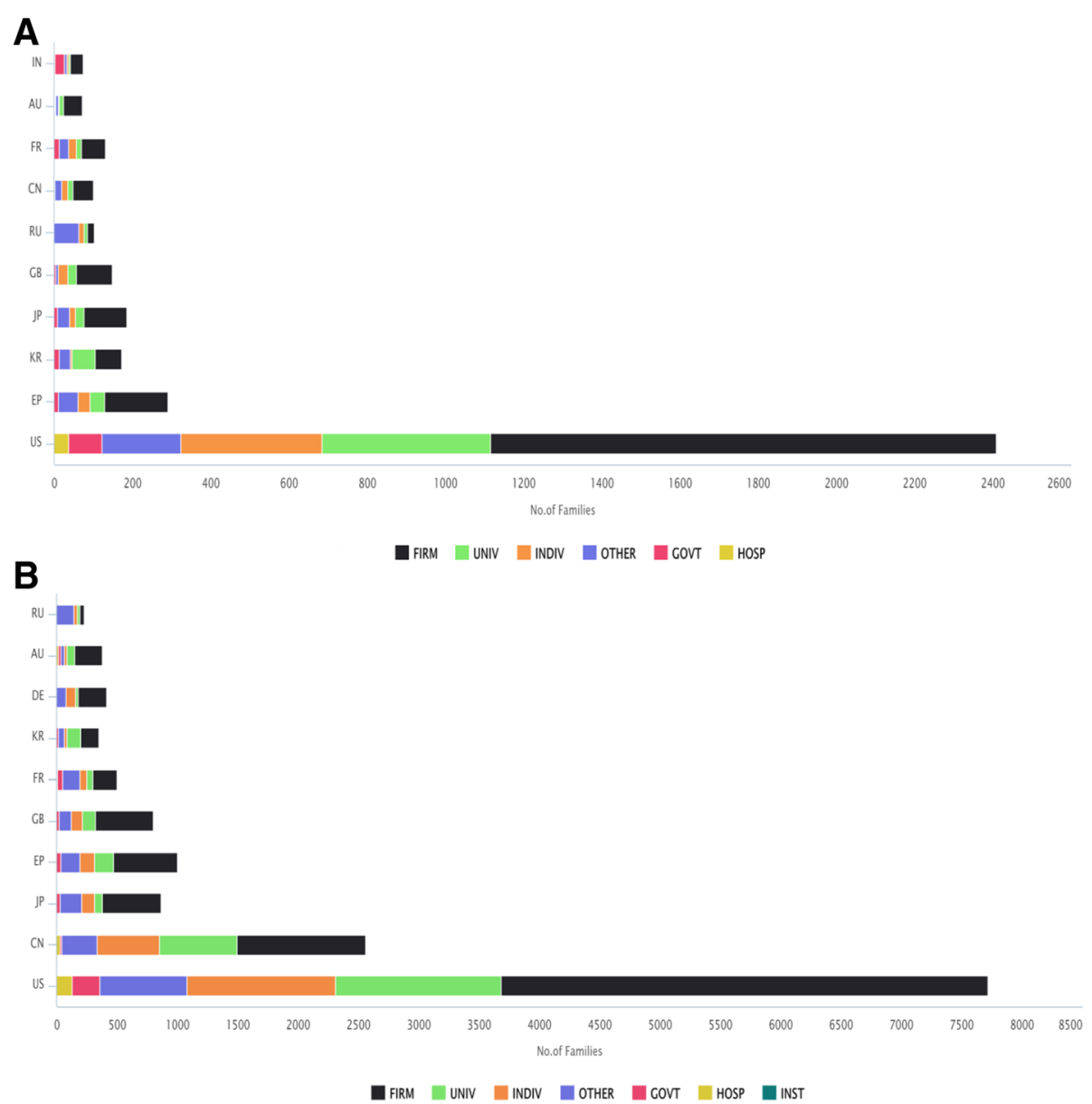

Fig. 4 Number of granted patent families (a) and the total patent families (b) for the top ten priority countries by types of assignee. a: Firm (firms), indiv (individuals), univ. (universities), inst (non-profit institutions), govt (governments) and hosp (hospitals) are assignee types. "Others" classify the assignee names or company names which do not fall under these categories (university, government, non-profit institution, hospital, individuals). Record numbers referring to the number of granted patent families. Priority countries are: US (United States), EP (European Union-European Patent Office), KR (Korea), JP (Japan), GB (Great Britain), RU (Russia), CN (China), FR (France), AU (Australia), IN (India). b: Firm (firms), indiv (individuals), univ. (universities), inst (non-profit institutions), govt (governments) and hosp (hospitals) are assignee types. "Others" classify all the assignee names or company names which do not fall under these categories (university, government, non-profit institution, hospital, individuals). Record numbers refer to the number of patent families. Priority countries are: US (United States), CN (China), JP (Japan), EP (European Union-European Patent Office), GB (Great Britain), FR (France), KR (Korea), DE (Germany), AU (Australia), RU (Russia)

yaws); while the third category lacks a clear trend due to the low number of filings (dracunculiasis, food-borne trematodiasis, human African trypanosomiasis, lymphatic filariasis, soil-transmitted helminthes, taeniasis). There was no significant increase in the number of granted patent families for any of the NTDs in the last 10 years. The figures of annual patenting trends for each NTD are presented in Additional file 2.

While the biphasic trends of IDM and PCT diseases appear to be similar, the patenting trends of these two groups reveal a slight noticable difference. In comparison with the PCT group, the IDM group show a more intense growth period and stagnation after 2008 (see Additional file 2).
Patent applications are not published until after 18 months, so information after 2014 is not presented in Fig. 1. Patents expire after 20 years. Legal status is important for information on commercial exploitability of patents. Analysis of current legal status of the patent families of NTDs, presented in Fig. 2, reveals that almost $50 \%$ of the patents are non-active. This fact suggests that investing in NTDs has a low commercial value. Among the 17 NTDs identified, the prevalence of non-active patents is noticeably high in leprosy, schistosomiasis, trachoma and trematodiasis (see Additional file 2).

Analyzing the top priority countries (countries where initial patent filing was submitted) for the granted patent families, it was observed that the main priority countries are the 


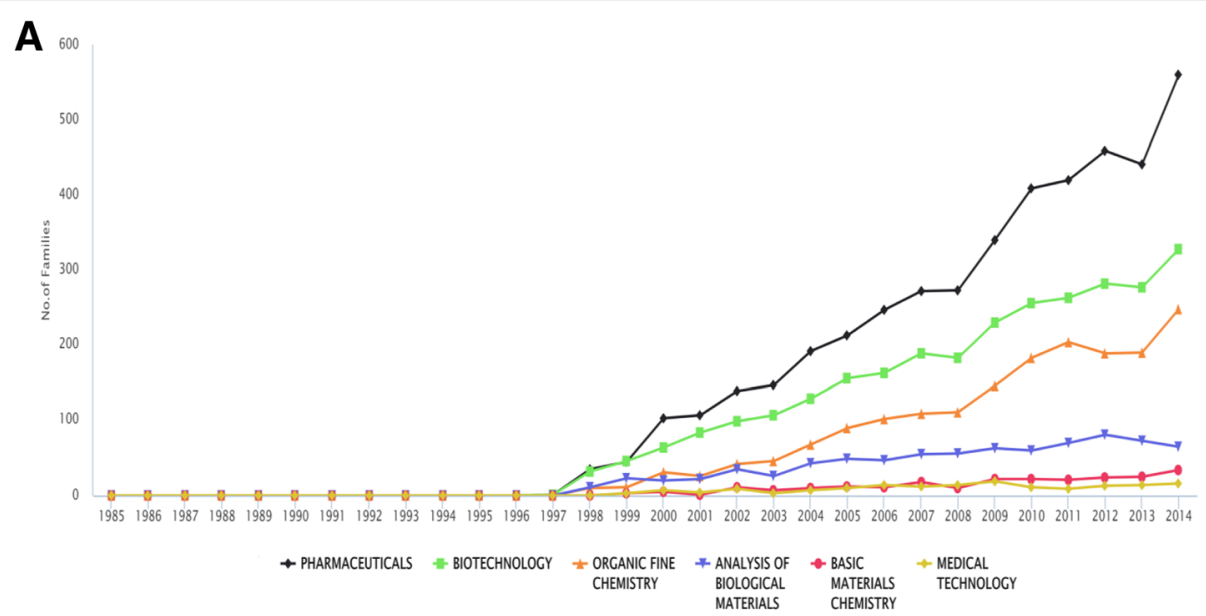

B

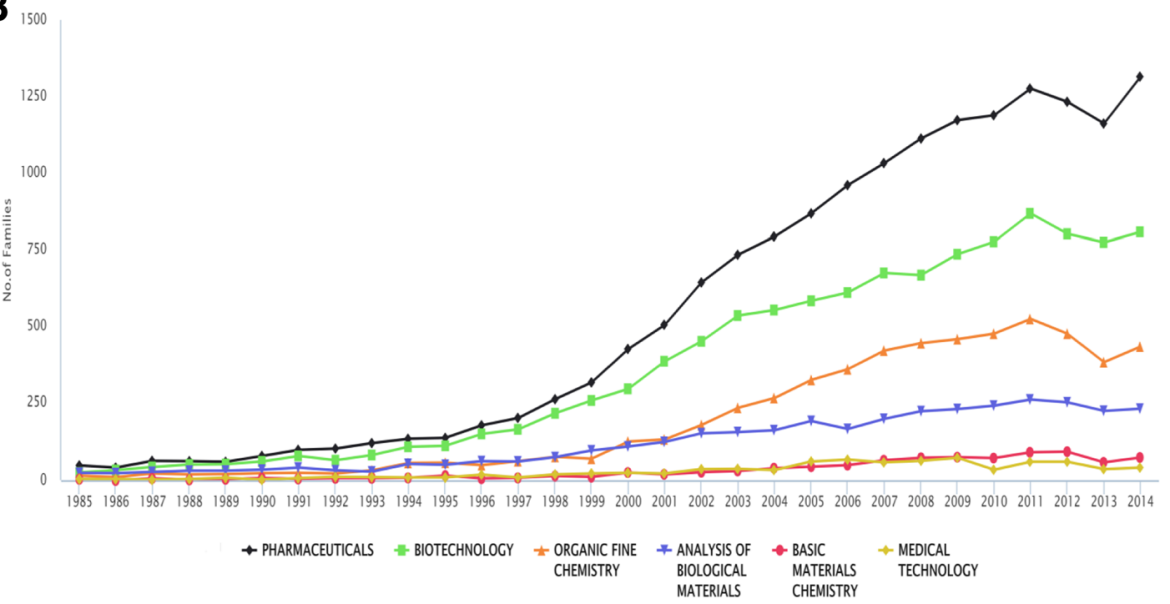

Fig. 5 Number of granted patent families (a) and the total patent families (b) for the technological subdomains over time. a: The main technological subdomains are pharmaceuticals, biotechnology, organic fine chemistry, analysis of biological materials, basic materials chemistry and medical technology. Contininous growth can be observed especially in the field of pharmaceuticals, biotechnology, organic fine chemistry. Record numbers refer to the number of granted patent families. $\mathbf{b}$ : The main technological subdomains are pharmaceuticals, biotechnology, organic fine chemistry, analysis of biological materials, basic materials chemistry and medical technology. Contininous growth can be observed especially in the field of pharmaceuticals, biotechnology, organic fine chemistry between 1985 and 2011 followed by stagnations/slight decline. Record numbers referring to the number of patent families

United States (US), European Union (EP), Korea (KR), Japan (JP) and Great Britian (GB) in the last 30 years. However, by focusing on the trend of total number of patent families, the leading countries are the US, China (CN), JP, EP, and GB. The gap between the first two priority countries is high, the US and China are with 6154 and 2423 patent families respectively. However, different patenting activity level of US and China can be detected by ratio of applications for patent families to granted patent families: 1898/3302 and 87/1525 respectively. With respect to NTDs, China appears as an emerging priority country compared with the US since 2010 as presented in Fig. 3. This trend is observed particularly for echinococcosis, rabies, schistosomiasis, and soil-transmitted helminthes. For example, China has a set priority for the soil-transmitted helminthiasis since 2010. Nonetheless, US has kept its leading role in intensive research on NTDs, such as leprosy, leishmaniasis and dengue. An interesting exception is observed for trematodiasis, which has Russia as its priority country.

In the US, firms hold a large percentage of patent families in comparison to other interest groups such as individuals, universities, governments, and institutes. In China, France, Korea, and Russia, more than $50 \%$ of patents and applications were assigned to entities other than firms. By focusing on the assignee types of granted patent families, the role of firms is dominant, except for France, Korea and Russia. In Korea, the universities, and in Russia, no specified assignees are the major patent holders. Distribution of assignee types among priority countries is assessed in Fig. 4.

Figure 5 provides an overview of the identified NTDs patent landscape in the form of technological fields. The main technological subdomains are pharmaceuticals, biotechnology, organic fine chemistry, analysis of 


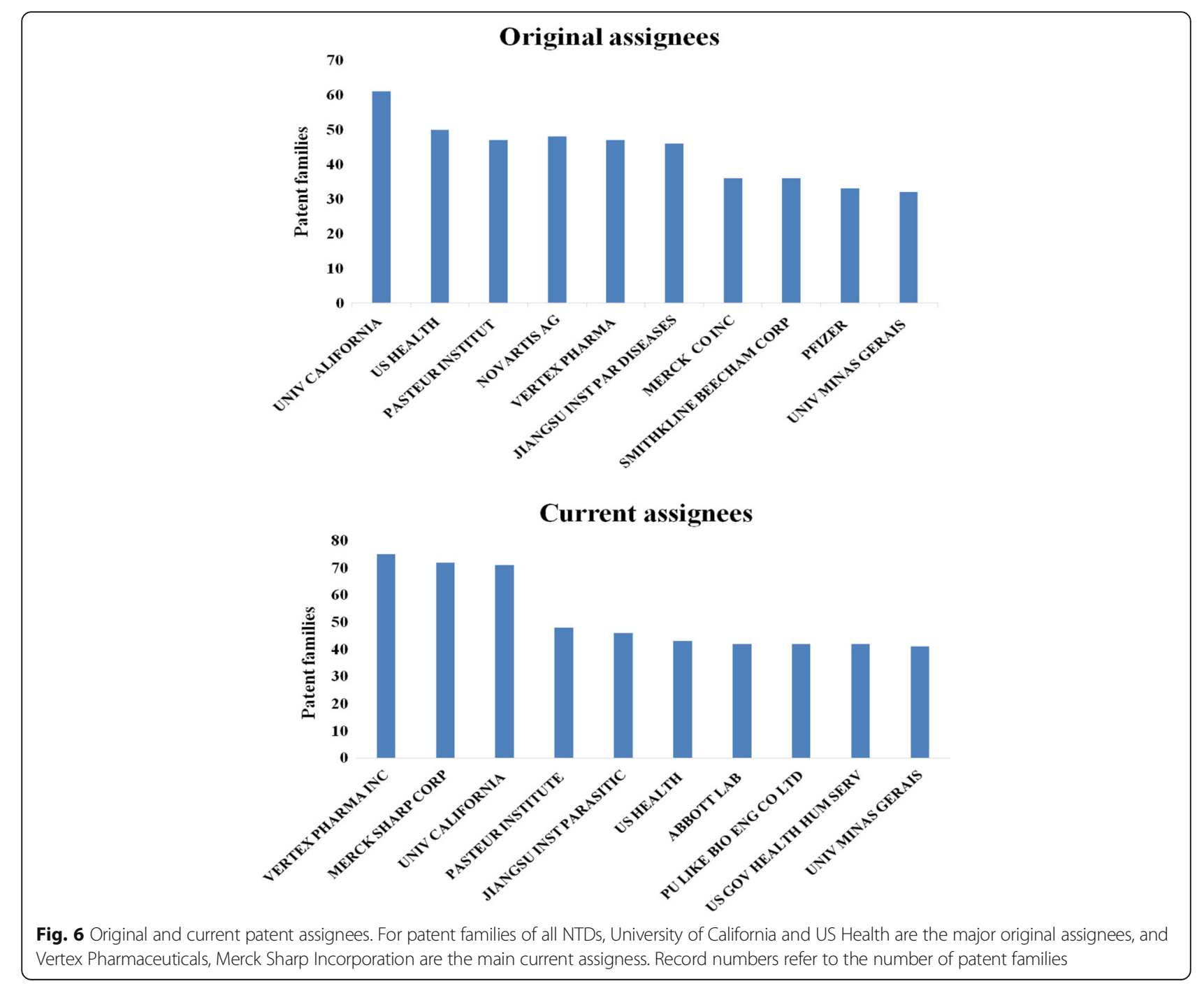

biological materials, basic materials chemistry and medical technology. According to the NTDs trends, pharmaceuticals and biotechnology accounted for most patent families filed in the last 30 years. These two fields have shown substantial growth since 1985 . Filings in organic fine chemistry have dropped in the last 10 years. The analysis of biological materials seems to be a popular field of innovation. Patent families for basic materials chemistry and medical technology have also shown substantial growth, in the overall analysis, but they account for a small portion of the filings. Focusing on the granted patent families, the stagnation/decline of the pharmaceuticals, biotechnology, organic fine chemistry fields are not yet present. The percentage of technical subdomains (pharmaceuticals, biotechnology, organic fine chemistry, analysis of biological materials, basic materials chemistry and medical technology) for alive versus non-alive patent families were similar. The highest proportions were observed in the pharmaceutical field, and the high proportion of dead patent families in the pharmaceutical is as a result of a decline in patent applications. Additionally, by comparing the technical subdomains of the IDM and PCT groups examined, it was observed that they have the same subdomains ranking order. However, while the hierarchy among subdomains of IDM is rather constant, there are changes in the positions of the subdomains of PCT. A very important observation is the clear decline in the number of patent families for pharmaceuticals and organic fine chemistry in the group of PCT.

The IPC classification of NTDs patents showed that class A61 is the most prominent class in which NTDs research patents are being categorised. In respect of this categorisation, A61K39/00 (medicinal preparations containing antigens or antibodies) is the most dominant IPC subgroup within the A61 class. Detailed research focus of each disease is presented by IPC subgroups in Additional file 2 . 
For a patent landscape analysis, analyzing the distribution of active patent applicants in a research field is important. With respect to NTDs research, a lack of dominant assignees (more than 33\% of patents) was observed (Fig. 6). The main original assignees for NTDs research are governmental institutions and universities, such as Univeristy of California (US) or Pasteur Institute (FR). Among current assignees, firms such as Merck, Vertex Pharma Inc. tend to take more financial risks on NTDs research.

\section{Discussion}

Long term trends reveal a continuous growth in the number of patent families of NTDs with a slight decrease after 2008. This continuous growth in trends is not uniform for all the NTDs. For example, there has been a significant decline in trachoma and leprosy research. Focusing on the granted patent families, a stagnation can be observed after 2008, not a decline. Additionally, previously marginalized diseases such as dracunculiasis were successful in attracting research interest in the last 10 years. However, global patenting trend is in sharp contrast with the findings on NTDs in this study. In the last 20 years, the total number of global patenting applications has tripled [23], but patent application increase on NTDs has not yet reached this rate. In order to better demonstrate the proportions of patenting activity, the number of patent families, corrected for normalized DALY (2015), was compared with a few other selected similarly robust social-, healthand economic impact diseases such as HIV/AIDS, malaria, cardiovascular diseases, cancers, and lung cancer [14]. The gap between patenting NTDs and cardiovascular diseases/ cancers is striking; the number of filed patents for cardiovascular diseases or cancer is at least 200 times larger than NTDs. Individual NTDs lag behind lung cancer, malaria or HIV/AIDS in patenting activities. Background data is presented in Additional file 3. R\&D interests among NTDs is very uneven. Leishmaniasis, dengue, schistosomiasis and rabies accounted for most of the growth in patenting activities. An obvious link between disease burden or availability of treatment (eg. PCT or IDM category) and patenting activity could not be identified in this study. This study finding shows that there is a limited attractiveness in this field, and this is consistent with previous articles on novel drug and vaccine landscape of NTDs by showing decrease as a tendency. Cohen et al., found 32 new chemical entities between 1975 and 1999, while between 2000 and 2009, there was only 26 newly approved drugs and vaccines for NTDs [24]. Pedrique et al., reported that most progress towards reducing the burden of NTDs focus on repurposing or reformulating existing drugs [25]. The Bill and Melinda Gates Foundation which has funded Policy Cures Research to conduct the last nine annual G-FINDER surveys also found stagnation in terms of new chemical entities of NTDs [26].
The analysis of this study also showed that the US is losing its position as a major priority country. This is consistent with the fact that China now drives global patent applications beginning with a new record achieved in 2015 [22]. Diversity between original and current assignees such as US Health vs Merck \& Co.; Pasteur vs Vertex Pharma Institute have been found in the patent database. This is a clear sign of emerging new interested parties. However, a high number of non-firm assignees indicates the limited level of industrial maturity in this field. A higher percentage of firms are assignees resident in the US in the field of NTDs compared to China. However, in China, there is a high proportion of patent families linked to univeristies or individuals which indicates high research activity.

An additional concern could be the high proportion of expired NTDs patents. Expired patents have limited strategic value to their assignees. This is because others cannot be excluded from using the invention(s) disclosed in the patent. However, information from expired patents may be relevant in the mitigation of NTDs, and can be used by non-governmental organizations (NGOs) or private-public partnerships who are key players to curbing the spread of NTDs [27].

The overall description of information contained in patent families was through technology fields. The main technology subdomains with emerging trends are pharmaceuticals and biotechnology. Many of the patents retrieved have strong focus towards medicinal preparations containing antigens or antibodies.

Based on the method of patent landscape analysis, patent families of each NTD were identified, merged and analysed to get overall insights regarding the trends, topics, and stakeholders in this field. This work could be a robust basis for future research in order to plan, monitor or justify decisions for R\&D policies.

Although, this paper argues that pursuing R\&D efforts in NTDs through the development of new innovations is important. $R \& D$ does not provide answers for several observed problems within the NTDs. It is important to pay attention to the broad social factors affecting NTDs; parallel improvements in hygiene, sanitation and access to medical care cannot be overlooked. Finding effective ways for development seems possible through publicprivate partnerships or new innovative alliances, established on case by case basis. Ways of addressing social challenges of NTDs may be found by taking good examples from HIV/AIDS management [28].

It is important to note that there are a number of methodological limitations in this study. There are limitations to the use of patent data as an indicator of technological development. This is primarily because not all inventions meet patentability standards, and inventors tend to rely on secrecy or other appropriate 
means to protect their inventions. Although, the developed search criteria facilitated the retrieval of patents of each NTD, it limited the absolute scope of a patent search. This simply mean that some patents might have not been included in the dataset intentionally. This is, however, a general limitation of all patent landscape analyses. Additionally, there is usually a time lag of at least 18 months between the first patent filing and the patent publication; and even longer time is used for granting.

Finally, R\&D analysis alone cannot show trends and future scencarios of research fields. Patent landscape analyses are quite simple, yet an effective way of planning and/or monitoring R\&D of NTDs.

\section{Conclusion}

The filing pattern of patent families reviewed strongly reveals limited efforts on research and development of NTDs, whereas it is crucial to intensify research efforts into NTDs. Involving new players, such as more NGOs may help to mitigate and reduce the burden of NTDs. In this work, patent landscape analysis has been presented as a reliable method that can be adopted for providing feedback on overall research progress of identified NTDs. R\&D incentives are not sufficient to solve the problem of inaccessibility of essential medicines in regions affected by NTDs. Strengthening the health systems, political and global health efforts will be of immense benefits to the most affected regions.

\section{Additional files}

Additional file 1: Final search terms of NTD. (PDF $23 \mathrm{~kb}$ )

Additional file 2: Detailed analyis of NTDs. (PDF $2490 \mathrm{~kb}$ )

Additional file 3: An inter-disease comparison of patenting activity. (PDF $20 \mathrm{~kb}$ )

\section{Abbreviation}

IDM: Innovative and Intensified Disease Management; IPC: International Patent Classification; MDA: Mass Drug Administraion; NGOs: NonGovernmental Organizations; NTDs: Neglected Tropical Diseases;

PCT: Preventive Chemotherapy and Transmission Control; R\&D: Research and Development; WHO: World Health Organization

\section{Acknowledgements}

We would like to express our gratitude to our colleague, Helga Bardos for the useful comments, remarks and engagement through the analysis of this work.

\section{Funding}

The work/publication is supported by the EFOP-3.6.1-16-2016-00022 project. The project is co-financed by the European Union and the European Social Fund.

Availability of data and materials

Not applicable

\section{Authors' contributions}

W and SS carried out the extraction and evaluation of patent families from Patseer using combination of different search terms related to each identified NTD. FT and VO uploaded and analyzed patent collection retrieved from Patseer in PatBase (an additional database and software). VO conceived of the study, and participated in its design and coordination and helped to draft the manuscript. All authors read and approved the final manuscript.

Ethics approval and consent to participate

Not applicable

Consent for publication

Not applicable

Competing interests

The authors declare that they have no competing interests.

\section{Publisher's Note}

Springer Nature remains neutral with regard to jurisdictional claims in published maps and institutional affiliations.

\section{Author details}

'Department of Preventive Medicine, Faculty of Public Health, University of Debrecen, Debrecen, Hungary. ${ }^{2}$ Federal University of Rio Grande do Norte, Natal, Brazil. ${ }^{3}$ Federal University of the Jequitinhonha and Mucuri Valleys, Natal, Brazil.

Received: 25 May 2017 Accepted: 24 October 2017

Published online: 14 November 2017

References

1. Savioli L, Daumiere D. Accelerating work to overcome the global impact of neglected tropical diseases: a roadmap for implementation. Geneva: World Health Organization; 2012.

2. World Health Organization. First WHO report on neglected tropical diseases: working to overcome the global impact of neglected tropical diseases. Geneva: the global impact of neglected tropical diseases. WHO press; 2010. http://apps.who.int/iris/bitstream/10665/44440/1/9789241564090_eng.pdf. Accessed 10 Oct 2017

3. Hotez PJ. NTDs V.2.0: "blue marble health"-neglected tropical disease control and elimination in a shifting health policy landscape. PLoS Negl Trop Dis. 2013;7:e2570.

4. World Health Organization: Accelerating work to overcome the global impact of neglected tropical diseases - A roadmap for implementation. (Crompton DWT ed. Switzerland; 2012.

5. Crompton DWT. Preventive chemotherapy in human helminthiasis: coordinated use of anthelminthic drugs in control interventions: a manual for health professionals and programme managers: World Health Organization. Geneva: WHO Press; 2006.

6. Webster JP, Molyneux DH, Hotez PJ, Fenwick A. The contribution of mass drug administration to global health: past, present and future. Philos Trans R Soc Lond Ser B Biol Sci. 2014:369:20130434.

7. Rosenberg M, Utzinger J, Addiss DG. Preventive chemotherapy versus innovative and intensified disease Management in Neglected Tropical Diseases: a distinction whose shelf life has expired. PLoS Negl Trop Dis. 2016:10:e0004521.

8. Mectizan Donation Program [http://www.mectizan.org/about/history]. Accessed 5 Oct 2017.

9. Savioli L, Daumerie D. Sustaining the drive to overcome the global impact of neglected tropical diseases: second WHO report on neglected tropical diseases (Vol. 2). World Health Organization. Geneva: WHO Press; 2006.

10. Hussain MA, Sitha AK, Swain S, Kadam S, Pati S. Mass drug administration for lymphatic filariasis elimination in a coastal state of India: a study on barriers to coverage and compliance. Infectious diseases of poverty. 2014;3:31.

11. Tchuem Tchuente LA. Control of soil-transmitted helminths in sub-Saharan Africa: diagnosis, drug efficacy concerns and challenges. Acta Trop. 2011; 120(Suppl 1):S4-11.

12. Smits HL. Prospects for the control of neglected tropical diseases by mass drug administration. Expert Rev Anti-Infect Ther. 2009;7:37-56.

13. Schwab AE, Boakye DA, Kyelem D, Prichard RK. Detection of benzimidazole resistance-associated mutations in the filarial nematode Wuchereria bancrofti and evidence for selection by albendazole and ivermectin combination treatment. The American journal of tropical medicine and hygiene. 2005;73:234-8. 
14. Kassebaum NJ, Arora M, Barber RM, Bhutta ZA, Brown J, Carter A, Casey DC, Charlson FJ, Coates MM, Coggeshall M, et al. Global, regional, and national disability-adjusted life-years (DALYs) for 315 diseases and injuries and healthy life expectancy (HALE), 1990\&\#x2013;2015: a systematic analysis for the global burden of disease study 2015. Lancet. 2016;388:1603-58.

15. Anthony Trippe. Guidelines for preparing patent landscape reports. In: Patent landscape reports. Geneva: WIPO. p. 2015.

16. Federico P, Heimerl F, Koch S, Miksch S. A survey on visual approaches for analyzing scientific literature and patents. IEEE transactions on visualization and computer graphics. 2017;23(9):2179-98.

17. Jana T, Dulakakhoria S, Bindal D, Mukherjee T, Tripathi A, Wadia N. Antimalarial patent landscape: a qualitative and quantitative analysis. Curr Sci. 2012:1162-74.

18. UNITAID. Malaria Diagnostics Landscape Update. In: World Health Organization (WHO); 2015.

19. Dara A, Sangamwar AT. Clearing the fog of anticancer patents from 1993-2013: through an in-depth technology landscape \& target analysis from pioneer research institutes and universities worldwide. PLoS One. 2014;9:e103847.

20. Patseer [http://patseer.com/]. Accessed 5 Oct 2017.

21. PatBase [https://www.patbase.com/login.asp]. Accessed 5 Oct 2017.

22. World Intellectual Property: Global Patent Applications Rose to 2.9 Million in 2015 on Strong Growth From China. Demand Also Increased for Other Intellectual Property Rights Organization [http://www.wipo.int/pressroom/ en/articles/2016/article_0017.html]. Accessed 5 Oct 2017.

23. Gridlogics Technologies Pvt Ltd: Worldwide patent filing trends (all authorities). Maharashtra 411045, India; 2015.

24. Cohen J, Dibner MS, Wilson A. Development of and access to products for neglected diseases. PLoS One. 2010;5:e10610.

25. Pedrique B, Strub-Wourgaft N, Some C, Olliaro P, Trouiller P, Ford N, Pécoul B, Bradol J-H. The drug and vaccine landscape for neglected diseases (2000\&\#x2013;11): a systematic assessment. Lancet Glob Health. 2013;1:e371-9.

26. G-Finder. Neglected Disease Research \& Development: the Ebola effect. In: G-FINDER reports (Policy Cures Research ed.; 2015.

27. Hotez P, Ottesen E, Fenwick A, Molyneux D. The neglected tropical diseases: the ancient afflictions of stigma and poverty and the prospects for their control and elimination. In Hot Topics in Infection and Immunity in Children III. Springer; 2006. pp. 23-33.

28. Padian NS, Holmes CB, McCoy SI, Lyerla R, Bouey PD, Goosby EP. Implementation science for the US President's emergency plan for AIDS Relief (PEPFAR). J Acquir Immune Defic Syndr. 2011;56(3):199-203.

29. Yotsu RR, Richardson M, Ishii N, 2016. Drugs for treating Buruli ulcer (Mycobacterium ulcerans disease). The Cochrane Library. Jpn J Infect Dis. 2013;66(2):83-8.

30. Rodriguez JB, Falcone BN, Szajnman SH. Detection and treatment of Trypanosoma cruzi: a patent review (2011-2015). Expert opinion on therapeutic patents. 2016;26:993-1015.

31. Salinas JL, Gonzales HV, Astuvilca J, Arce-Villavicencio Y, Carbajal-Gonzalez D, Talledo L, Willig JH. Long-term albendazole effectiveness for hepatic cystic echinococcosis. The American journal of tropical medicine and hygiene. 2011;85:1075-9.

32. Beesley NJ, Williams DJL, Paterson S, Hodgkinson J. Fasciola Hepatica demonstrates high levels of genetic diversity, a lack of population structure and high gene flow: possible implications for drug resistance. Int J Parasitol. 2017:47:11-20

33. Unciti-Broceta JD, Arias JL, Maceira J, Soriano M, Ortiz-González M, Hernández-Quero J, Muñóz-Torres M, De Koning HP, Magez S, GarciaSalcedo JA. Specific cell targeting therapy bypasses drug resistance mechanisms in African trypanosomiasis. PLoS Pathog. 2015;11:e1004942.

34. Deep DK, Singh R, Bhandari V, Verma A, Sharma V, Wajid S, Sundar S, Ramesh V, Dujardin JC, Salotra P. Increased miltefosine tolerance in clinical isolates of Leishmania donovani is associated with reduced drug accumulation, increased infectivity and resistance to oxidative stress. PLoS Negl Trop Dis. 2017;11:e0005641.

35. Williams DL, Gillis TP. Drug-resistant leprosy: monitoring and current status. Lepr Rev. 2012;83:269.

36. Cobo F. Determinants of parasite drug resistance in human lymphatic filariasis. Revista Española de Quimioterapia. 2016;29(6):288-95.

37. Doyle SR, Bourguinat C, Nana-Djeunga HC, Kengne-Ouafo JA, Pion SD, Bopda J, Kamgno J, Wanji S, Che H, Kuesel AC. Genome-wide analysis of ivermectin response by Onchocerca volvulus reveals that genetic drift and soft selective sweeps contribute to loss of drug sensitivity. PLoS Negl Trop Dis. 2017;11:e0005816.

38. da Silva VBR, Campos BRKL, de Oliveira JF, Decout JL, de Lima MDCA. Medicinal chemistry of antischistosomal drugs: Praziquantel and Oxamniquine. Bioorg Med Chem. 2017;25(13):3259-77.

39. Krücken J, Fraundorfer K, Mugisha JC, Ramünke S, Sifft KC, Geus D, Habarugira F, Ndoli J, Sendegeya A, Mukampunga C. Reduced efficacy of albendazole against Ascaris Lumbricoides in Rwandan schoolchildren. International Journal for Parasitology: Drugs and Drug Resistance. 2017;7:262-71.

40. Diazgranados-Sanchez J, Barrios-Arrázola G, Costa J, Burbano-Pabon J, Pinzón-Bedoya J. Ivermectin as a therapeutic alternative in neurocysticercosis that is resistant to conventional pharmacological treatment. Rev Neurol. 2008;46:671-4

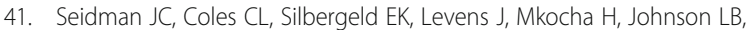
Muñoz B, West SK. Increased carriage of macrolide-resistant fecal E. Coli following mass distribution of azithromycin for trachoma control. Int J Epidemiol. 2014;43:1105-13.

42. Šmajs D, Paštěková L, Grillová L. Macrolide resistance in the syphilis spirochete, Treponema pallidum ssp. pallidum: can we also expect Macrolide-resistant yaws strains? The American journal of tropical medicine and hygiene. 2015;93:678-83.

43. University of Washington: Institute for Health Metrics and Evaluation. Seattle; 2015. http://www.healthdata.org/. Accessed 10 Oct 2017.

44. World Health Organization: Fact sheets: neglected tropical diseases. Geneva; 2016. http://www.who.int/mediacentre/factsheets/en/. Accessed 10 Oct 2017.

45. World Health Organization: Investing to Overcome the Global Impact of Neglected Tropical Diseases: Third WHO Report on Neglected Tropical Diseases 2015. vol. 3. Geneva; 2015. http://apps.who.int/iris/bitstream/10665/ 152781/1/9789241564861_eng.pdf. Accessed 10 Oct 2017.

\section{Submit your next manuscript to BioMed Central and we will help you at every step:}

- We accept pre-submission inquiries

- Our selector tool helps you to find the most relevant journal

- We provide round the clock customer support

- Convenient online submission

- Thorough peer review

- Inclusion in PubMed and all major indexing services

- Maximum visibility for your research

Submit your manuscript at www.biomedcentral.com/submit
) Biomed Central 